\title{
Mathematics for early childhood education: a model of mathematics teaching through EDI software
}

\author{
Edivalda Pereira da Silva Martins ${ }^{1}$, Ocileide Custódio da Silva ${ }^{2}$ \\ ${ }^{1,2}$ Production Engineering Post-Graduation Program, Universidade Federal do Amazonas - UFAM - BRAZIL
}

\begin{abstract}
A matemática é uma disciplina fundamental na formação dos alunos e sua inserção na sociedade. Por este motivo, a busca de metodologia que promovam o aumento do índice de aprendizagem desta matéria possui grande relevância. Neste sentido, as novas estratégias para o ensino da matemática na educação infantil aliada ao avanço tecnológico incitam as escolas a buscarem novas tecnologias que facilitam e melhorem o processo de aprendizado. Este trabalho propõe um modelo experimental para o ensino da matemática através de um software para auxiliar no aprimoramento do aprendizado da matemática nos anos iniciais da educação infantil, medir como está sendo desenvolvidas as aulas pelo educador e auxiliar a gestão na tomada de decisão para a melhoria do processo. Para tanto, será desenvolvida uma metodologia baseada em software de aplicação. A efetividade do método proposto será mensurada com o auxílio de ferramenta da qualidade. Com isso, espera-se identificar os principais fatores que influenciam no aprendizado e aplicar o software a ser desenvolvido para o ensino-aprendizado da matemática na educação infantil.
\end{abstract}

Keywords: Child. Early Childhood Education.Mathematics. Software.

\section{Introducão}

A qualidade no setor de serviços baseia-se na diferença entre a expectativa de um cliente com o serviço a ser prestado e sua percepção de como ele é prestado [1]. Os autores [2] afirmam que as ações em qualidade nos serviços norteiam as organizações, minimizando fracassos, aumentando o poder de competitividade e incrementando o processo. Compartilham da mesma ideia [3], segundo os quais a qualidade em serviços pode ser compreendida como atender as necessidades dos clientes, provendo soluções para os problemas, no qual o cliente avalia todo o processo de prestação do serviço.

Os serviços no setor da educação podem ser oferecidos pela iniciativa privada, segunda a Constituição no seu artigo 205, fala que a educação será "promovida e incentivada com a colaboração da sociedade". Ou seja, percebeu-se que o Estado, por si só, não é capaz de oferecer tal serviço universalmente e, portanto, conta com o auxílio dos particulares na consecução deste fim.O acesso à prestação de serviço no setor de educação infantil teve um crescimento expressivo na pré-escola, embora os mais ricos continuem a ter mais acesso, houve aumento significativo da frequência dos mais pobres à pré-escola [4].

Segundo dados do [5], a qualidade do serviço prestado para educação infantil pelas escolas privadas tem uma qualidade em torno de $83 \%$ conforme pesquisa realizada no período de 2005-2006. Entretanto, nas escolas públicas, matricular ou não uma criança de 0 até 5 anos na instituição de Educação Infantil é um ato de livre vontade das mães e dos pais e/ou responsáveis pelas crianças.

A definição de qualidade da educação e a seleção de critérios que possibilitem medidas de qualidade são temas em constante discussão no campo educacional. Na educação infantil, este é um debate bastante atual, que comporta diferentes posicionamentos nos meios especializados. Segundo um estudo de [6], baseado em dados da PNAD, mostrou que as condições materiais das creches e pré-escolas particulares são sensivelmente melhores do que aquelas encontradas na rede pública: "há mais instituições particulares que têm livros, textos, vídeos, televisões, computadores e laboratórios".

A realidade do ensino da educação infantil no Amazonas, não é diferente do restante do Brasil, pois a criança só frequenta a escola a partir de 06 anos de idade. Segundo a Prova Brasil Evolução dos estudantes em Manaus, entre 2011 e 2013, nas provas de Matemática e Português foi de, respectivamente, $3 \%$ e 5\%. No conjunto de todas as escolas, estaduais e municipais no Estado, entre 2011 e 2013, no aprendizado de Português, houve uma evolução de 5 pontos percentuais (28\% para 33\%) entre os alunos até o $5^{\circ}$ ano e de 3 pontos percentuais (16\% para 19\%) entre os alunos até o $9^{\circ}$ ano. Em Matemática, a evolução foi de 3 pontos percentuais (22\% para $25 \%$ ) entre os alunos até o $5^{\circ}$ ano. E a evolução foi zero entre os alunos até o $9^{\circ}$ ano. Portanto, a partir das informações da Prova Brasil, o MEC e as secretarias estaduais e municipais de Educação podem definir ações de aprimoramento da qualidade do ensino para direcionar os recursos técnicos e financeiros às áreas identificadas como prioritárias. Ressaltamos ainda, que nas escolas estaduais somente $9 \%$ aprenderam adequadamente a resolução de problemas de Matemática até o $9^{\circ}$ ano e nas escolas municipais esse índice ficou em torno de $4 \%$. 
Para [7],a matemática é utilizada por todos os seres humanos deste a sua infância. Para o docente fica a tarefa de redescobrir elementos e opções que contribuam para o desenvolvimento e aprendizado da matemática. Aprender a contar e a calcular são os primeiros passos vitais em direção as competências da matemática[8]. A criança independente da raça, possuem conhecimentos primários referentes à matemática e essa habilidade nasce com elas, só precisando de um mínimo de apoio para se desenvolver [8]. É na educação infantil que a criança inicia o seu desenvolvimento lógico e cognitivo, promovendo assim, a construção do seu conhecimento.

A matemática é uma disciplina fundamental na formação dos alunos e sua inserção na sociedade. Por esse motivo se faz necessário o uso de novas tecnologias para o desenvolvimento do aprendizado de matemática, trazendo assim, para este meio a criança que não tem interesse ou está com dificuldade. A educação infantil é a primeira etapa da Educação Básica, ela estabelece as bases da personalidade humana, da inteligência, da vida emocional e da socialização, e estas são as primeiras experiências da vida as quais marcam mais profundamente a pessoa. A necessidade de priorizar a educação das crianças de 0 a 5 (zero a cinco) anos em estabelecimentos específicos de Educação Infantil, decorre principalmente, devido ao fato de ser comprovado cientificamente que a formação da inteligência ocorre a partir do nascimento. A criança deve receber tratamento adequado nessa idade, a fim de exercer funções em outras áreas como: Matemática, Linguagem, Música, e demais áreas psicomotoras.

É na educação infantil que a criança irá construir seu vínculo com o mundo. Apoiando esta afirmativa [9], fala que "é necessário que à criança cresça inteiramente em todos os aspectos, e que esta necessidade venha a ser atendida através de uma educação estruturada". [10], afirmam que apesar da educação ter observado o avanço tecnológico e inovador, quase não houve mudança no sistema educacional.

É interessante que seja oferecido às crianças uma variedade de situações e inovações, de modo que estimule o seu aprendizado nos anos iniciais da educação infantil. Conforme [10], o ambiente de aprendizagem em sala de aula deve mudar constantemente para enfrentar os desafios e potencialidades oferecidas pelas novas tecnologias e compreensões de como as crianças aprendem.

A educação no Brasil é um campo de conhecimento que precisa de melhorias, pois é uma área que desenvolve um conjunto de competências nos indivíduos e essas competências serão levadas no decorrer do seu desenvolvimento pessoal e profissional. Conforme dados da Prova Brasil, o alto índice de notas baixas na disciplina de matemática, nos leva a buscar novos métodos de ensino para que possamos mudar o cenário da educação no Brasil.

Em suma, verificou que a literatura temos vários métodos para o ensino da educação infantil. No entanto, verificou-se que na unidade em estudo existem crianças com dificuldade no aprendizado da matemática.Dentre os tipos de métodos existentes, optou-se por estudar um conjunto de processos do setor educacional e neste contexto, surgiu o problema norteador da pesquisa: De que forma podem ser utilizadas as ferramentas tecnológicas para o ensino-aprendizado da matemática nos anos iniciais da educação infantil?

\section{Materiais E Métodos}

Este estudo de campo foi realizado a unidade de Educação Dr. Francisco Garcia, faz parte da Rede SESI de Educação do Amazonas, localizada na Avenida Danilo de Matos Areosa, s/n Distrito Industrial, na cidade de Manaus / AM, Brasil.A Educação Infantil na modalidade creche e pré-escola atende aos interesses e necessidades das crianças, desenvolvendo suas potencialidades. No espaço educacional, a criança é considerada como sujeito social, interativo e produtora de conhecimentos por meio de práticas alinhadas ao cotidiano da sala de aula.

Quanto à natureza, essa pesquisa é definida como aplicada, que segundo [11], a pesquisa aplicada tem como motivação a necessidade de produzir conhecimento para aplicação de seus resultados, com o objetivo de "contribuir para fins práticos, visando o desenvolvimento de novos produtos, serviços ou processos".

Para atender ao objetivo deste estudo, optou-se por uma pesquisa descritiva, que para[12], envolvem a análise, o registro, levantamento bibliográfico e a interpretação dos fatos sem a interferência do pesquisador.

Quando a abordagem do estudo optou-se por uma abordagem quantitativa, que segundo [13], é fundamentada, por sua base de caráter descritivo, de análise e de interpretação das informações e dados recolhidos durante o processo investigatório.

Quando ao método utilizado, esse estudo define-se como pesquisa de campo, onde foi observado como é o ensino-aprendizagem da matemática para crianças nos anos iniciais da educação infantil que, conforme[14], é uma investigação empírica realizada no local onde ocorre ou ocorreu um fenômeno ou que dispõe de elementos para explicá-lo. O procedimento metodológico aplicado neste trabalho foi realizado conforme apresentado na Figura 1. 
Figura 1 - Descrição do Processo

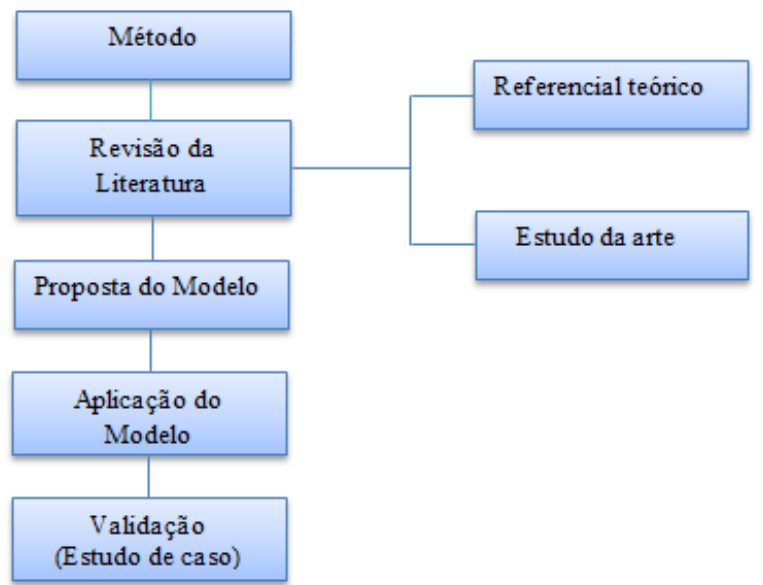

Fonte: Adaptado pelo autor (2016)

A aplicação e validação do modelo foram feita através do estudo de campo realizado na Escola SESI de Educação Dr. Francisco Garcia, a fim de testar a eficiência do modelo proposto de software, executou-se sua aplicação, esse procedimentofoi considerado um experimento, segundo [15], as pesquisas experimentais constituem o mais valioso procedimento disponível aos cientistas para testar hipóteses que estabelecem reação de causa e efeito.

Assim, considerando que o estudo se baseia em um experimento e que para sua aplicação, fizeram-se uso de técnicas estatísticas para se obter o universo a ser aplicado, compreende-se que o estudo resultou em fins confiáveis para futuros estudos nessa área. Considerando que a população (ou universo) "é a totalidade dos itens ou objetos considerados" [16] e buscando isonomia na pesquisa, definiu-se como população todos os alunos matriculados $1^{\circ}$ e $2^{\circ}$ período que totalizou 640 crianças matriculadas. No entanto, foiconsiderada somente uma amostra de 193 crianças para aplicação do software experimental de matemática.

Levantando em consideração que esta amostra é uma proporção da quantidade de alunos matriculados no $1^{\circ}$ e $2^{\circ}$ período da Unidade de Educação Francisco Garcia, utilizou-se na composição da amostra a técnica probabilística para amostragem aleatória simples, com índice de confiança de $94 \%$ e um erro amostral tolerável para o estudo foi de $6 \%$ calculado com fulcro nas seguintes fórmulas:

$\eta_{\mathrm{o}}=\underline{1}$

$\mathrm{E}_{0}^{2}$

Onde:

- $\eta_{\mathrm{o}}$ é a primeira aproximação do tamanho da amostra

- $\mathrm{E}^{\circ} \mathrm{e}$ o erro amostral tolerável (Ex.: 6\%; =0,06)

$$
=\frac{N \cdot \eta_{0}}{N+\eta_{0}}
$$

Onde:

- N é o número de elementos da população = alunos

- né o tamanho da amostra

$\mathbf{E}_{0}=0,06$

$$
\begin{array}{r}
=\frac{1}{06^{2}}=-277,77 \\
\mathrm{~N} . \mathrm{r} \quad=\frac{\mathrm{x}}{\mathrm{N}+\ldots \mathrm{277,77}}=
\end{array}
$$

= 193 crianças da educação infantil na idade de 04 a 05 anos que participaram da aplicação do estudo. 


\subsection{Qualidade na educação}

A palavra qualidade na educação tem diferentes significados, que dependem do ponto de vista sob o qual é analisado [17]. A palavra tem sido aplicada em diferentes situações, na indústria ou na prestação de serviços, cada uma com definições particulares, podendo significar: "fazer certo da primeira vez", "ausência de defeitos", "atender a expectativa do cliente", e várias outras definições. O conceito pode ser diferente dependendo do ponto de vista sob o qual é analisado, podendo ser o de quem oferece ou recebe um produto ou serviço. Entender o conceito de qualidade é fundamental quando se pretende fazer sua gestão.

Segundo [18], a qualidade em educação pode e deve ser vista sob a perspectiva das seis dimensões da qualidade (qualidade intrínseca, custo, atendimento, moral, segurança e ética).

[19], considera que a qualidade na educação está baseada em cinco pontos fundamentais, que são:

a) docentes saudáveis, bem nutridos e aptos a ensinar e aprender, apoiados por suas famílias e comunidades;

b) ambiente de ensino saudável, protetor, com fontes de informação e instalações que contemplem a igualdade de ensino e de acesso para os gêneros;

c) conteúdo adequado para o currículo e para a aquisição de competências básicas, especialmente em leitura, matemática e competências para a vida, com conhecimentos que contemplem gênero, saúde, nutrição, prevenção do HIV/AIDS e paz;

d) processos de ensino voltados para a criança, em salas de aula, escolas e conteúdos que facilitem o aprendizado e reduzam as diferenças;

e) resultados que privilegiem o conhecimento, habilidades e atitudes relacionadas às metas de educação e participação positiva na sociedade.

Mas, mesmo com tantas definições diferentes há um consenso de que qualidade na educação não é medida apenas pelo bom aproveitamento dos estudantes, mas é uma consequência de processos bem conduzidos que levam ao aprendizado, ao oferecer um ambiente adequado para a aquisição do conhecimento e de docentes bem preparados e instrumentalizados para a educação.

Segundo [20], a gestão é um elemento decisivo da eficiência escolar, sendo difícil de encontrar no sistema educacional brasileiro. Portanto, é necessário tomar uma posição gerencial moderna e eficaz, para que as mudanças criativas e inovadoras também soprem para a educação.

A educação é o começo do processo gerador da qualidade e deve também atuar como provedor para a melhoria eficiente, efetiva e eficaz de seus próprios objetivos educacionais informados nos projetos políticos pedagógicos.

\subsection{Projeto político pedagógico - em ação na área da matemática}

O projeto político pedagógico mostra a visão macro do que a instituição escola pretende ou idealiza fazer, seus objetivos, metas, estratégias permanentes e processos avaliativos, tanto no que se refere às suas atividades pedagógicas, como às administrativas no âmbito das políticas implementadas. Segundo [21], $\mathrm{O}$ projeto político-pedagógico dá o norte, o rumo, a direção; "Ele possibilita que as potencialidades sejam equacionadas, deslegitimando as formas instituídas"

Neste sentido, o projeto político-pedagógico passa a ser um direcionador, um rumo para as ações da escola, através de uma ação intencional que deve ser construída coletivamente. Ele é denominado de político porque reflete as opções e escolhas de caminhos e prioridades na formação do cidadão, como membro ativo e transformador da sociedade na qual esta inserida. Buscando organizar as funções educativas para que a escola atinja de forma eficiente e eficaz suas finalidades [21].

Assim, o projeto político pedagógico é um instrumento de fundamental importância para definição do currículo da escola e neste consta a parte referente à área de matemática da educação infantil e séries iniciais, tendo em vista que trata-se de um ramo do saber caracterizado pela abstração, precisão, rigor lógico nos seus resultados e conclusões. [7], afirmam que a matemática é usada por todos os humanos deste sua educação infantil até a vida adulta.

Os desafios do mundo contemporâneo, principalmente os gerados pelas transformações do avanço das tecnologias, são transferidos para escola em forma de saberes a serem discutidos, avaliados e aperfeiçoado para o aprendizado da criança.

Nesse contexto situa-se o ensino da matemática que tem sido alvo de muitas pesquisas na área pedagógica relativa à produção de materiais áudio visual, com utilização das novas tecnologias, métodos e técnicas do fazer pedagógico. [9], afirmam que a criança independente da raça, é dotada de conhecimentos primários referente a matemática e geometria básica. Essas habilidades nascem com elas, precisando de um mínimo de apoio para se desenvolver. Segundo [22], a mão do homem foi a primeira calculadora, pois devido aos dez dedos das mãos o ser humano foi desenvolvendo o domínio das ciências exatas e por consequência a matemática. 


\subsection{A criança, as mãos e os números}

Ao longo do desenvolvimento da criança e em sua natureza humana, ela abriga uma particula do próprio desenvolvimento da humanidade. Na história temos estudos que demonstram que o corpo do homem foi a primeira ferramenta a ser usada como instrumento de construção do número [22].

As mãos constituem naturamente um instrumento natural de aprendizado, ela constitui um modelo mais simples que a humanidade dispõe para realizar a contagem até dez. [22], afirma que "a mão do homem se apresenta, assim, como a 'máquina de contar' mais simples e mais natural que existe. E é por isso que ela exercerá um papel considerável na gênese do nosso sistema de numeração". E o mesmo ainda descreve que em função da especificidade de cada um de seus dedos, a mão pode também ser vista como uma verdadeira sucessão de unidades abstratas obtidas consecutivamente a partir da primeira, através da associação suplementar de uma unidade. O que significa que, com a mão, os dois aspectos complementares do número inteiro tornam-se completamente intuitivos: ela atua como instrumento que permite a passagem insensível do número cardinal ao número ordinal correspondente, ou inversamente.

A matemática originalmente, segundo [23], surgiu como parte da vida diária do homem, e se há validade no princípio biológico da "sobrevivência do mais apto" a persistência da raça humana provavelmente tem relação com o desenvolvimento de conceitos matemáticos. Para os estudiosos sempre fica a tarefa de adicionar sempre algo ao que veio antes, sem com isso, retirar ou perder o princípio de tudo.

Portanto, a valorização das mãos deve ser considerada, pelas áreas pedagógicas, como sendo uma das aptidões mais importante na construção do número pela criança, pois através das mãos elas vão começar a ter noção de sistema númerico e vão poder desenvolver as primeiras estratégias de contagem e na operalização da matemática conforme Figura 2.

Figura 2 - A mão como instrumento natural de cálculo.

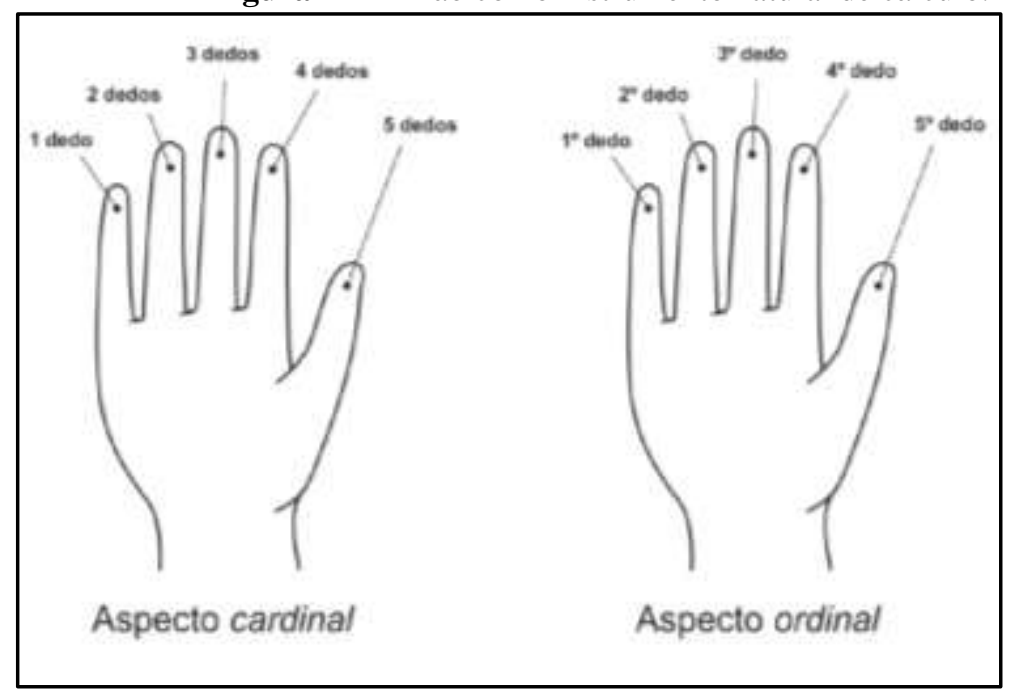

Fonte: IFRAH, 2005, p. 51.

Portanto, a utilização das mãos para o ensino através do lúdico ajuda a criança a desenvolver maneiras e métodos de contar, sendo um modelo cognitivo expressado pela criança na fase da aprendizagem da matemática [24].

\subsection{Jogos educativos e lúdicos}

Utilizar jogos educativos e/ou lúdicos no ambiente educacional infantil é conduzir para o processo de ensino e aprendizagem condições de elevar e potencializar a exploração na construção do conhecimento, a partir do lúdico, do encanto, da competência de introdução ativa e motivadora. É também um recurso que possibilita, através da observação, constitui uma visão de desenvolvimento das crianças em conjunto ou em particular, cada uma armazenando suas competências do modo das locuções, igualmente como de suas competências igualitárias e das soluções pessoais e afetivas. As crianças através dos jogos educativos e/ou lúdicos desenvolvem maneiras e métodos de contar, sendo um modelo cognitivo expressado pela criança na fase da aprendizagem da matemática.Para [25], ao buscarmos conceitos importantes de matemática no desenvolvimento de jogos, pode ser de grande importância para a criança, pois poderá ampliar suas aptidões e capacidades para se obter novos conhecimentos. 
Segundo [26], define três relações entre jogo infantil e educação, antes da revolução romântica; o primeiro se refere à recreação, no qual era utilizado apenas como meio de relaxamento e de diversão; segundo referente ao uso de jogos para favorecer o ensino de conteúdos escolares, no qual tinha o objetivo de divulgar princípios de moral, ética e conteúdos de várias disciplinas; o terceiro correspondia ao diagnóstico da personalidade infantil e recurso para ajustar o ensino às necessidades infantis, no qual procurava a melhor maneira para garantir a aprendizagem. $\mathrm{O}$ mesmo afirmar, que o brinquedo educativo chama atenção para algumas considerações quando eles assumem uma função lúdica e educativa.

1. Função do jogo ou brinquedo: ajuda na brincadeira, distração e até no desagrado, quando pego espontaneamente.

2. Função educacional: a brincadeira desenvolve a criança em sua sabedoria, suas informações e sua percepção do ensinar, qualquer coisa que complete o indivíduo em seu saber, seus conhecimentos e sua apreensão do mundo.

3. Personalidade infantil: ajustar o ensino às necessidades infantis, procurando uma melhor maneira para garantir o aprendizado.

Ainda, na visão dessa autora, o uso do brinquedo/jogo para fins pedagógicos, é de grande relevância para o processo de ensino e aprendizagem, e para o desenvolvimento da criança. Ao permitir a ação involuntária (cordialidade), a constituição de seus aspectos mentais (cognitivo), à manipulação de objetos e desempenho de ações sensório-motoras (físico) e a trocas de interações (social), estará contemplando as várias maneiras do perfil da criança ou suas diversas habilidades, assim contribuindo para a aprendizagem e conhecimento infantil.

Nesse sentido, é interessante que seja oferecido às crianças uma variedade de situações e inovações, de modo que estimule o seu aprendizado nos anos iniciais da educação infantil. Conforme [11], o ambiente de aprendizagem em sala de aula deve mudar constantemente para enfrentar o desafio e potencialidades oferecidas pelas novas compreensões de como as pessoas aprendem. Esta aplicação adequada de conhecimentos é o que define a tecnologia educacional e viver de acordo com esta definição é a marca da fase de evolução.

\subsection{Inovação na educação pedagógica}

Com o avanço das tecnologias de informação e comunicação, bem como o aparecimento de novas metodologias e técnicas de ensino, levando ao surgimento de ferramentas tecnológicas a serviço da educação. A inovação na educação pedagógica sugere modificações nos métodos pedagógicos de aprendizagem da criança. $\mathrm{O}$ professor que era acostumado a utilizar o giz em sala de aula, passou a ter o auxilio das ferramentas tecnológicas para um melhor desempenho do aprendizado. No entanto, é essencial que o educador saiba utilizar os recursos tecnológicos de forma que valorize suas atividades e o processo de ensino aprendizagem, pois com a inovação e o avanço tecnológico, a criança tem uma facilidade em manusear os jogos que foram desenvolvidos para computadores, tablete e outros aparelhos eletrônicos.

Para [11], tecnologia educacional envolve a aplicação de ideias de várias fontes para criar os melhores ambientes possíveis de aprendizagem para os alunos. Segundo[27], a ampla difusão da tecnologia digital na vida cotidiana impõe aos sistemas de ensino para educar seus alunos para estar ciente de seu impacto na sociedade e no meio ambiente. Porque seu uso tornou-se essencial, as demandas também foram colocadas em escolas para fazer os alunos tecnologicamente alfabetizado. Segundo [28], as tecnologias de informáticas estão alterando a formar de se aprender na escola, demonstrando processo no que as crianças aprendem. No entanto, a tecnologia digital na educação continua a oferecer desafios políticos para os países em desenvolvimento [29].

Para [30], o ensino onde a criança tem contato com o computador podem ter efeitos fundamentais, é um novo relacionamento onde ela pode desenvolver importante domínio do conhecimento que podem ser fundamentais para o seu desenvolvimento. Em matemática, especificamente, o computador pode proporcionar prática e promover o pensamento logico e desenvolver competências na contagem e classificação [31].

Segundo [32], utilizar o computador como recurso tecnológico no período de educação infantil, não prevalece somente o reflexo em disciplinas matemáticas. Começa a formar um indivíduo não ouvinte e sim participante e questionador. Não aceitante a resultados preestabelecidos.

[33], afirma que, podemos incluir computadores na atividade desenvolvida com a criança. No entanto, devemos da ênfase ao aprendizado da matemática. O uso de ferramentas tecnológicas para o ensino da Matemática tem o objetivo de fazer com que as crianças gostem de aprender essa disciplina, mudando a rotina da classe e despertando o interesse do aluno envolvido, permitindo que o processo de aprendizagem seja interessante e até divertido.Desse modo, percebe-se que a utilização de uma ferramenta tecnológica para o ensino da matemática é algo que permite a criança desenvolver o raciocínio logico a compreensão de conceitos matemáticos, de tal forma, que se torna algo prazeroso e não somente para o professor, mas também para criança. 


\subsection{Avanço tecnológico e ambiente virtual}

Atualmente estamos inseridos em um mundo onde se apresentam tecnologias que sofrem mudanças constantes. Com isso a escola atual deve buscar novas tendências pedagógicas e tecnológicas para atender da melhor forma possível estas necessidades [34].

A utilização de tecnologias para o desenvolvimento do aprendizado nos anos inicia da educação infantil devem ser analisados antes de se colocar em prática, pois, o professor deve conhecer o jogo, verificar em que ele pode ajudar na aprendizagem da criança e principalmente se vai atender aos objetivos e se é válido para a disciplina a ser utilizada.Para [11], a evolução serve como um lembrete que o sistema educacional deve permanecer sempre em evolução e adaptar-se a manter a sua eficácia. $\mathrm{O}$ autor afirma que o ambiente de aprendizagem em sala de aula deve mudar constantemente para enfrentar o desafio e potencialidades oferecidas pelas novas compreensões de como as pessoas aprendem.

Deste modo, podemos destacar os softwares que são criados e/ou preparados para o aprendizado do individuo, uma vez que eles possuem recursos que ajudam na aprendizagem diversa e possuem soluções tecnológicas que podem prender a atenção da criança, tornando o aprendizado mais prazeroso.Para [35], os meios interativos podem tornar a aprendizagem para criança mais atrativa e envolvente, trazendo para este ambiente que não estão totalmente interessadas na aprendizagem. De acordo com o Referencial Curricular Nacional para a Educação Infantil, na escola de instrução para criança, podem ser desenvolvidas maneiras de se ensinar através de brincadeiras de aprendizagem coordenadas por um adulto. Sendo importante, que esse ensinamento seja de maneira associada para o acréscimo intelectual infantil. Deste modo, ensinar e educar são criar situações favoráveis que irão contribuir para o relacionamento interpessoal da criança, proporcionando um ambiente favorável para a interação nas atividades visando concordância, aceitação, consideração e confiança [36].

Portanto, podemos afirmar que a instituição de educação infantil, deve adequar o ambiente escolar as novas experiências tecnológicas, onde as crianças possam desenvolver atividades voltadas à realidade nos quais preparam o individuo e auxiliam no seu desenvolvimento intelectual, motor e afetivo e para a tomada de decisão do gestor para avaliação do processo de ensino da educação infantil.

\subsection{Estudo da arte}

Ultimamente, o uso de ferramentas digitais nas diferentes faixas de idade, embasados em teorias de aprendizagem e abordagens pedagógicas tem sidoapontado como uma boa estratégia para auxiliar no processo de ensino-aprendizagem em diversas áreas do conhecimento [37]. Estes recursos podem contribuir para o desenvolvimento de conhecimento e habilidades cognitivas, entre outras, como a resolução de problemas, o pensamento estratégico e a tomada de decisão [38].A compreensão de software educacional mostram diversas pesquisas aplicadas em diversos países e áreas incluindo na área da saúde, onde é possível adequar a metodologia de software educacional para ser utilizado na área de enfermagem para o ensino aprendizado nos diversos processos da área.

[39], relatou sua experiência utilizando software educacional para ser utilizado no ensino de enfermagem sobre a semiotécnica e semiologia do recém-nascido pré-termo, desta forma visando agregar e analisar as informações relevantes para a tomada de decisão e para o desempenho eficiente de todas as suas funções.[40], relatou a construção de uma hipermídia educacional para o ensino do procedimento de medida da pressão arterial, pois a medida da pressão arterial é um procedimento imprescindível na avaliação do sistema cardiovascular.

[41], relatou a construção de um software educacional para ensinar a técnica de cateter urinário. O software desenvolvido visava apresentar informações sobre a técnica de inserção do cateter vesical de demora por meio de um recurso interativo para ser utilizado como uma ferramenta auxiliar no processo de aprendizagem de alunos de vários cursos em programas de enfermagem. Seu uso também pode ser estendido aos professores e enfermeiros em situações de treinamento, melhoria, reciclagem praticar para o cateter urinário.

[42], relatou o desenvolvimento de um software didático para ser utilizado no ensino de saúde mental, visando o ensino-aprendizagem de conteúdos específicos e de formação geral na área da saúde mental para alunos de enfermagem.Para validação, participaram 27 avaliadores, sendo seis integrantes da Liga Acadêmica de Saúde Mental e Psiquiatria da Universidade Federal de São João Del Rei (estudantes do curso de Medicina e de Enfermagem), 14 estudantes do $7^{\circ}$ e $9^{\circ}$ períodos de Enfermagem da Universidade Federal de São João Del Rei e sete professores de Saúde Mental e Psiquiatria de cursos de graduação em Enfermagem de universidades públicas (mestres ou doutores em Enfermagem Psiquiátrica ou Saúde Mental). Os avaliadores participantes da validação caracterizam grupos representativos, direta ou indiretamente, da população-alvo do software. A validação do jogo foi aprovada pelo Comitê de Ética em Pesquisa da FUNEDI, parecer 23/2010.

[43], construiu uma ferramenta digital educativa com características de jogos (gamificação) para representar, e demonstrar o processo de gerenciamento dos resíduos sólidos e que o manejo incorreto dos resíduos sólidos pode provocar vários impactos ambientais. Esta ferramenta de aprendizagem visa sua utilização 
como recurso didático a ser aplicado na educação formal e não formal visando trabalhar a temática de resíduos sólidos em escolas e organizações conforme gerenciamento de resíduos sólidos instituído pela Lei $n^{\circ} n^{\circ}$ $12.30 / 2010$.

Todavia vários estudos e pesquisas mostram a aplicação de software educacional em vários segmentos de negócio como no ensino da enfermagem, contribuindo para facilitar o ensino e consequentemente a possibilidadede uma melhoria da assistência em saúde.

\section{Resultados}

Durante a análise dos métodos para o ensino da matemática na educação infantil percebeu-se que cada instituição desenvolve o seu método de ensino com base no seu projeto político pedagógico que incluem: brincadeiras, lúdico, jogos, computadores, entre outros, para o desenvolvimento do aprendizado da criança.

A Tabela 1 e o Gráfico 1, tem-se os resultados obtidos referentes aos métodos utilizados no ensino da matemática na educação infantil.

Tabela 1 - Métodos utilizados para o Ensino da Educação Infantil

\begin{tabular}{ccc}
\hline Categoria & Quantidade & Porcentagem \\
\hline Brincadeiras & 10 & $28 \%$ \\
\hline Computadores & 05 & $14 \%$ \\
\hline Fantoches & 06 & $16 \%$ \\
\hline Jogos & 05 & $14 \%$ \\
\hline Lúdicos & 10 & $28 \%$ \\
\hline \hline Total & 36 & $100 \%$
\end{tabular}

Gráfico 1 - Métodos utilizadosna EducaçãoInfantil

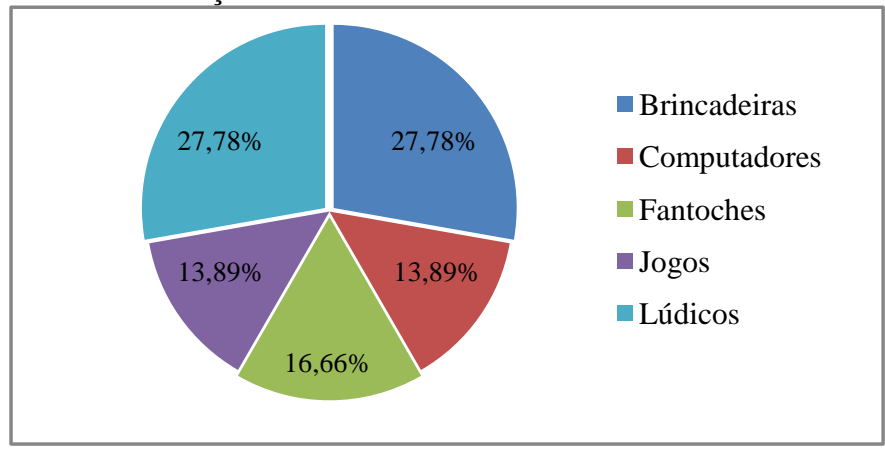

Fonte: Adaptado pelo autor (2016)

Através deste foi possível visualizar os métodos que são utilizados pelas escolas para o ensino aprendizado da matemática na educação infantil. Deste modo, conforme tabela 1 e gráfico 1 pode-se se observar que o computador e o jogo são poucos utilizados para o ensino da criança da educação infantil, principalmente na rede pública de ensino. Na instituição particular de ensino o uso do computador é uma atividade alternativa, visando o contato da criança com a tecnologia e um diferencial que a escola oferece ao seu cliente.

Com isso é possível constata a necessidade do desenvolvimento de software experimental para auxiliar no ensino da matemática na educação infantil eque possa auxiliar também o gestor na tomada de decisão do processo de ensino matemática na escola em estudo. O desenvolvimento do método experimental para auxiliar no ensino-aprendizado da matemática na educação infantil foi realizado utilizando-se ferramentas da qualidade adequadas às etapas do ciclo PDCA.

O uso do Ciclo PDCA é amplamente utilizado no gerenciamento de processos ou serviço [44], [45], [46], [47], [48]. Assim, para a construção do modelo experimental de software, consideraram-se as quatro fases do modelo PDCA: identificação do problema, observação, análise, plano de ação, execução, verificação, padronização e conclusão.

Para a condução da construção do modelo experimental de software, a literatura [48, 49] indica que seja feito um planejamento de experimentos. Desta forma, procurou-se construir um modelo guiado pelas etapas desta metodologia, que são: reconhecimento do problema, escolha do tipo de procedimento experimental, execução do experimento, análise de dados e conclusões.

O modelo experimental de software foi desenvolvido em uma interface principal na linguagem Java, com um layout contendo imagens de personagens infantis visando o interesse da criança pelo uso. 
A proposta dessa metodologia tem em vista contribuir para: (a) identificar a criança que está com dificuldade no aprendizado da matemática; (b) medir como estão sendo desenvolvidas as aulas pelo educador;(c) auxiliar a gestão na tomada de decisão para melhoria do processo.

Com base no estudo desenvolvido que utilizou uma amostragem não probabilística para aplicação do software na unidade de estudo. Foi realizado um levantamento do perfil de conhecimento da criança em relação ao conhecimento de aparelhos eletrônicos, de modo,a saber, se fazia parte do cotidiano de cada criança conforme Quadro 1.O levantamento foi realizado em sala de aula pelo pesquisador juntamente com as professoras de cada turma. No decorrer das atividades foram apresentadas para crianças imagens de dispositivos eletrônicos como: telefone celular, notebook, tablet, computador, etc, no momento da apresentação a criança falaria sobre sua familiaridade com cada aparelho e qual gostava mais e pretendia utilizar.

Quadro 01 - Perfil do conhecimento das turmas

\begin{tabular}{|c|c|c|c|}
\hline $\begin{array}{l}\text { Idade de } 04 \text { a } 05 \\
\text { anos }\end{array}$ & $\begin{array}{l}\text { Períodos: } 1^{\circ} \text { e } 2^{\circ} \text { período } \\
\text { escolar }\end{array}$ & Descrição do perfil da turma & Turmas \\
\hline $\begin{array}{l}\text { Perfil do } \\
\text { conhecimento }\end{array}$ & $\begin{array}{c}\text { Conhece e já usou } \\
\text { dispositivos eletrônicos: } \\
\text { telefone celular, } \\
\text { notebook, tablet, } \\
\text { computador, etc? }\end{array}$ & $\begin{array}{l}\text { As crianças das turmas do } 1^{\circ} \text { e } 2 \text { períodos, embora } \\
\text { pequenas demonstraram conhecer aparelhos eletrônicos; } \\
\text { algumas brincam com o telefone celular do (pai e/ou } \\
\text { mãe); tem familiaridade com computador, sabe utilizar o } \\
\text { mouse; conhece os números de } 1 \text { a } 10 \text {; gostam de realizar } \\
\text { atividades no laboratório de informática; algumas } \\
\text { brincam também em tablets e computadores em suas } \\
\text { residências; tivemos crianças que demonstraram ter } \\
\text { dúvidas em relação aos números de } 1 \text { a } 10 \text {. }\end{array}$ & $\begin{array}{l}55 \text { a } 691^{\circ} \\
\text { Período } \\
70 \text { a } 802^{\circ} \\
\text { Período }\end{array}$ \\
\hline
\end{tabular}

Fonte: Adaptado pelo autor

Com base no levantamento observou-se que o computador não oferece problemas relevantes para crianças, ao contrário elas demonstram ter muito interesse em usa-los. Portanto, visualizando o cenário de interesse da criança por aparelhos eletrônicos e novas tecnologias, foi realizada a aplicação do modelo software para auxiliar no aprendizado da matemática nos anos iniciais da educação infantil.Antes da aplicação do software foi realizada a apresentação da metodologia para o gestor da escola e coordenadores.

A aplicação do software foi realizada no laboratório da unidade em 06 sessões conforme quadro 2.

Quadro 2- Cronograma de aplicação do software

\begin{tabular}{|c|c|c|c|}
\hline Data & Mês & Ano & \multirow{2}{*}{ Turmas } \\
\hline 28.09 & Setembro & 2015 & \multirow{2}{*}{55 a $691^{\circ}$ Período } \\
\hline 14.10 & Outubro & 2015 & \\
\hline 30.10 & Outubro & 2015 & \multirow{2}{*}{70 a $802^{\circ}$ Período } \\
\hline 09.11 & Novembro & 2015 & \\
\hline 24.02 & Fevereiro & 2016 & \\
\hline 14.03 & Março & 2016 & \\
\hline 24.03 & Março & 2016 & \\
\hline 11.04 & Abril & 2016 & \\
\hline
\end{tabular}

Fonte: Adaptado pelo autor

No primeiro momento foi explicado para as crianças o funcionamento do software. Foram apresentadas todas as telas através do data show para que a criança compreende-se o funcionamento e suas características. No momento da aplicação cada criança tinha uma ficha de acompanhamento, pois cada acerto elou erro foi anotado na folha de acompanhamento de cada criança. Segue abaixo telas do software:

Figura3 - 1 $\mathbf{1}^{\text {a }}$ Tela de apresentação

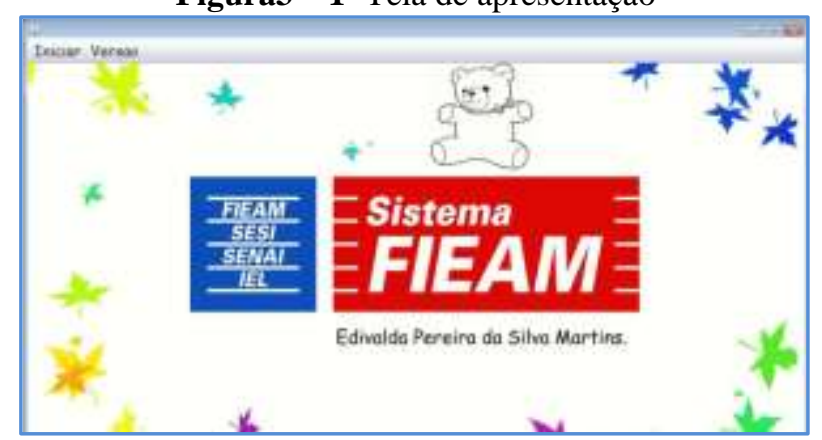

Fonte: Adaptado pelo autor (2015) 
Figura $4-2^{a}$ Tela apresenta a mão com os númerosindicando cada dedo

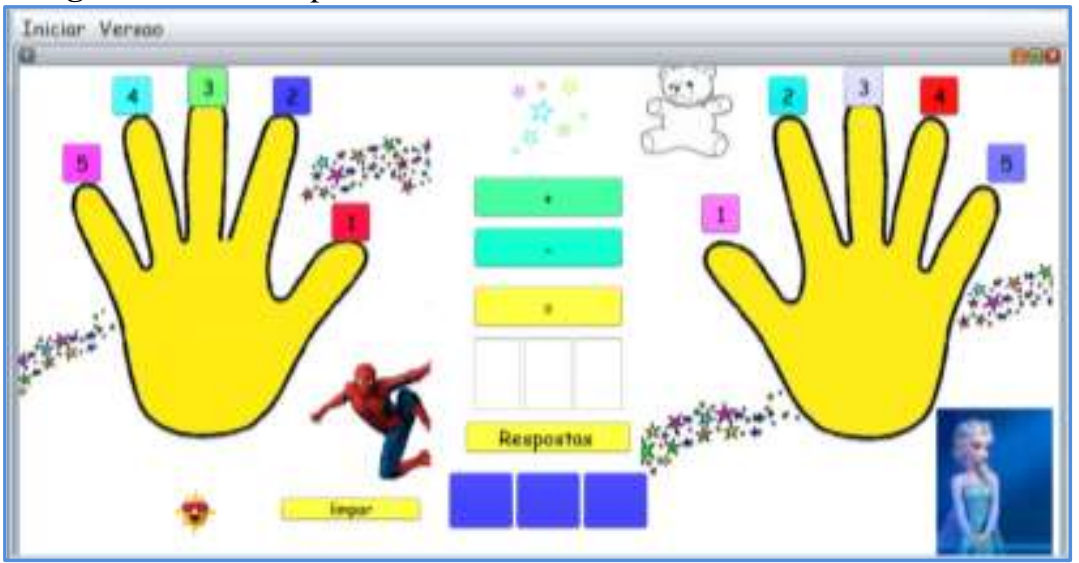

Fonte: Adaptado pelo autor (2015)

* Nesta primeira etapa a criança deverá clicar em um dedo do lado esquerdo e depois acionar o sinal de adição ou subtração, para escolha do cálculo que será realizado pelo sistema, em seguida deverá clicar em um dedo do lado direito e por fim clicar no símbolo do sinal de igualdade (=).

Figura $5-3^{\text {a }}$ Tela o software mostrará três opções de resposta

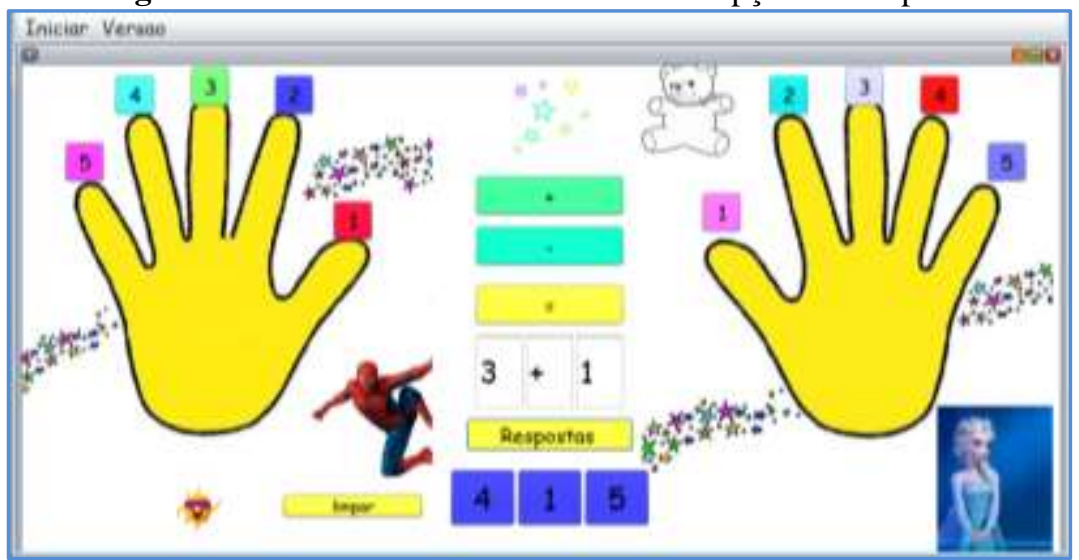

Fonte: Adaptado pelo autor (2015)

* Realizada a primeira etapa pela criança, o sistema irá mostrar três possíveis respostas e a criança deverá clicar em cima do resultado que acredita ser o correto.

Figura $6-4^{\text {a }}$ Tela sistema mostrará um sorriso e uma medalha para o acerto.

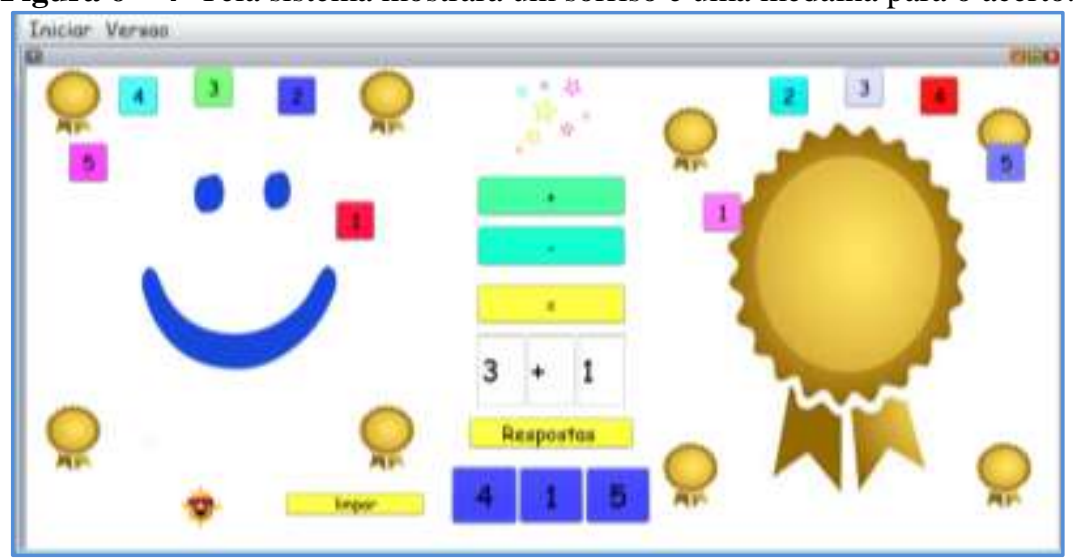

Fonte: Adaptado pelo autor (2015)

* Caso a criança tenha acertado o cálculo, na tela aparecerá um sorriso e uma medalha, demostrando que a criança acertou a soma ou subtração. 
Figura $7-5^{\text {a }}$ Tela sistema mostrará uma carinha triste para o erro no cálculo

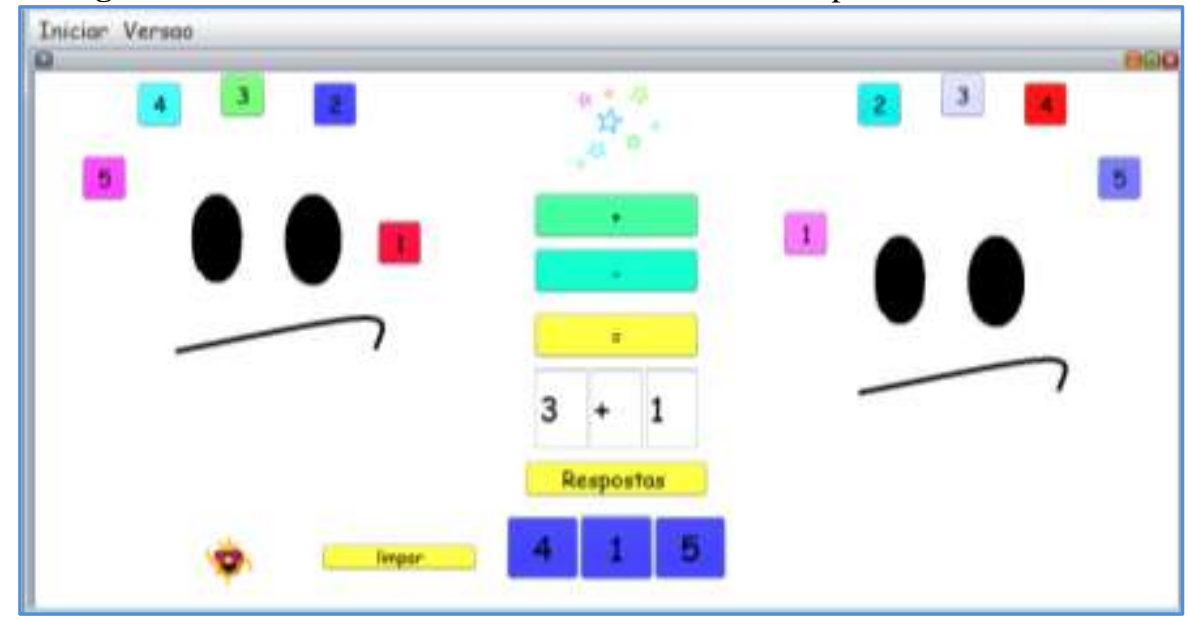

Fonte: Adaptado pelo autor (2015)

* Caso a criança tenha errado o cálculo, na tela aparecerá uma carinha triste, incentivando a tentar novamente. Para iniciar um novo cálculo a criança limpa a tela clicando no limpar e inicia novamente.

Para [50], a criança desde pequena vive num contexto social envolvido por diversas tecnologias como computadores, televisão, rádio, jogos eletrônicos, celulares e entre outros, e automaticamente ela já adquire hábitos, atitudes e habilidades que fazem parte de uma identidade moderna, sendo assim a escola precisa utilizar os recursos tecnológicos dentro da sala de aula, pois é um processo de aprendizagem que respeita o meio em que a criança vive.

Para mensurar a efetividade do modelo proposto foram utilizadas ferramentas da qualidade durante a pesquisa em estudo. Segundo [51], ferramentas da qualidade são instrumentos que nos auxiliam na mensuração e apresentação dos resultados, visando o apoio à tomada de decisão por parte da gestão. Através do Brainstorming e Diagrama de Ishikawa foi realizado o levantamento do processo em estudo conforme Quadro 3 e Figura 8 respectivamente.

Quadro 3 - Roteiro utilizado durante sessão de Brainstorming na escola em estudo $1^{\circ}$ e $2^{\circ}$ períodos.

\section{ROTEIRO PARA BRAINSTORMING- ESCOLA}

Objetivo: Coletar informações relevantes para o desenvolvimento do estudo, como: identificar como é desenvolvido o ensino-aprendizagem da matemática.

Roteiro: 1) Explicar aos professores o objetivo e natureza do estudo. 2) Instigar a opinião deles, através das perguntas elaboradas e, 3) Possibilitar espaço para eles emitirem sua opinião, ao passo, que serão feitas as devidas anotações das informações repassadas.

Perguntas:

1) Qual o maior problema para o desenvolvimento do ensino-aprendizagem da matemática?

2) Quais atividades são realizadas com as crianças?

3) Descrever o procedimento que é realizado quando um aluno tem dificuldade para aprender matemática.

4) Quais são os fatores que interferem no desenvolvimento do aprendizado da matemática?

5) Como é sinalizado para professora do laboratório que a criança está com dificuldade no ensinoaprendizagem da matemática?

6) Em que momento a psicopedagoga é solicitada para avaliar o desempenho do aprendizado de uma criança?

Fonte: Adaptado pelo autor (2015) 
Figura 8 - Diagrama de Ishikawa da escola estudo.

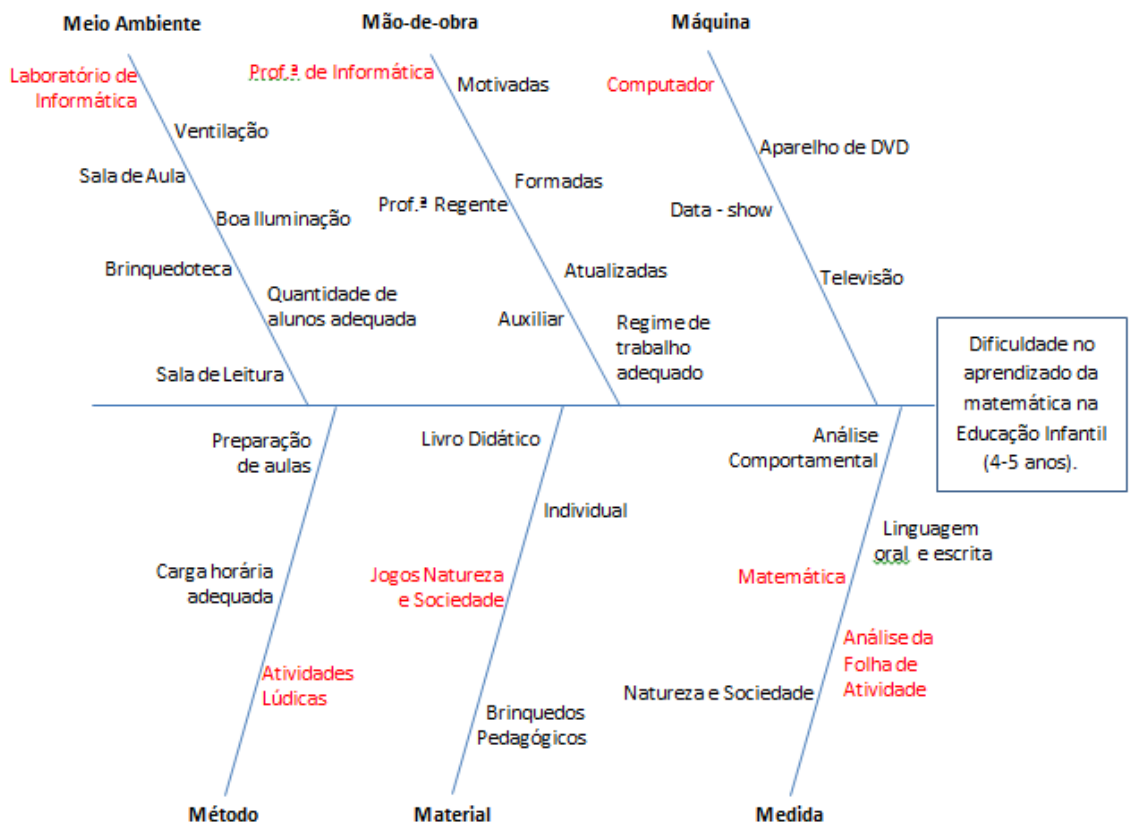

Fonte: Adaptado pelo autor (2005)

Através da folha de acompanhamento da atividade foi possível construir o Diagrama de Pareto, com o objetivo de identificar o quantitativo de crianças que apresentam dificuldade no aprendizado da matemática na escola em estudo conforme Diagramas 1 e 2 abaixo:

Diagrama1 $^{\circ}$ Período - Unidade de Educação Dr. Francisco Garcia

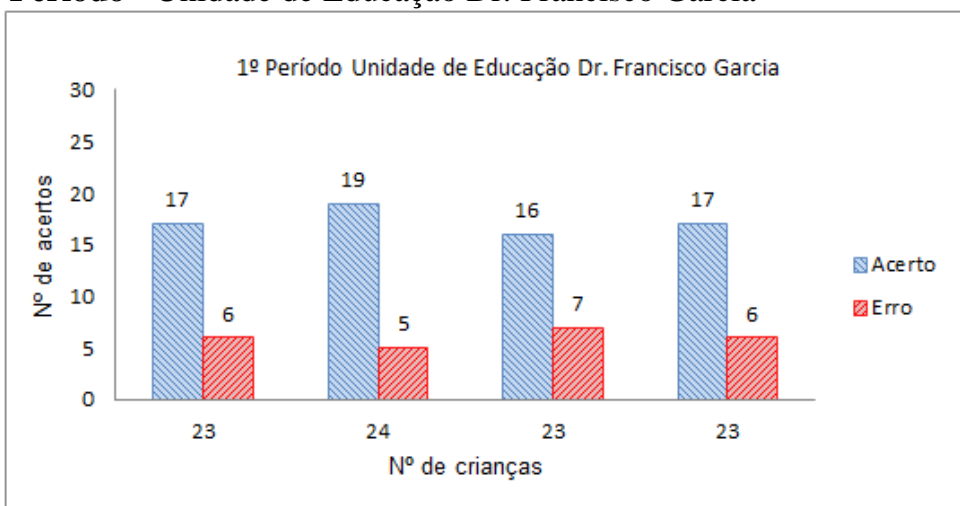

Fonte: Adaptado pelo autor (2015) 


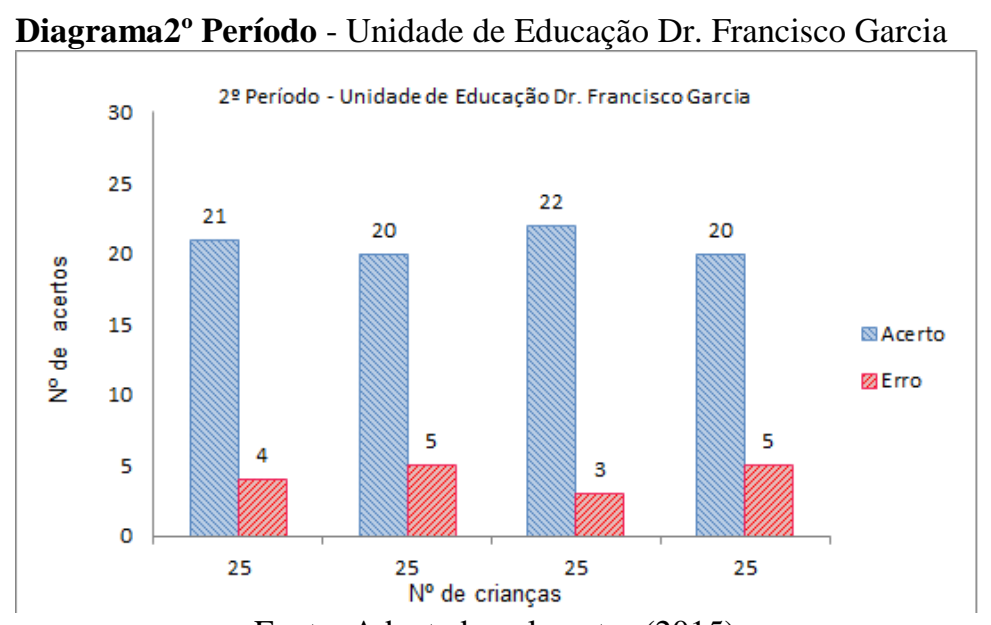

Fonte: Adaptado pelo autor (2015)

No momento da aplicação do software é possível perceber como a criança tem uma afinidade com o computador, pois o ambiente virtual deixa a criança mais ativa e a cada jogada e acerto ela queria sempre realizar uma nova operação de soma ou subtração visando mostrar para o coleguinha ao lado quantos acertos ela obteve no momento do uso do software.Portanto, neste contexto o uso de software para auxiliar no desenvolvimento do ensino da matemática por crianças que estão na fase de aprendizagem é de grande valia, pois o uso da tecnologia pela criança no seu ambiente escolar a deixa desinibida, fazendo com que ela não tenha medo de errar e busque sempre a construção do seu próprio conhecimento.

Para a gestão da escola o uso da ferramenta vem ao encontro da sua visão que é "ser referência na educação", pois através do resultado dos dados fornecidos pelo universo que participou da aplicação do estudo que mostrou um índice de $25,8 \%$ das crianças do primeiro período não conhecem os numerais e/ou não sabem realizar os cálculos de soma ou subtração. No resultado das crianças do segundo período esse índice ficou em torno de $17 \%$. Portanto, a gestão da escola poderá avaliar o desenvolvimento do aprendizado da matemática e tomar decisões de melhorias do processo que visam o desenvolvimento do aprendizado da criança da educação infantil, e que essas melhorias não sejam somente no aprendizado da matemática, mas nos aspectos cognitivo, motor social, politico, pois tem a capacidade de incentivar o raciocínio lógico, saber lidar com situações matemáticas, adquirir confiança e por fim é na educação infantil que se promove a construção do conhecimento da criança.

\section{IV.Conclusões}

O presente artigo possibilitou a aplicação de um modelo experimental para o desenvolvimento do ensino e aprendizagem da matemática como também uma maneira de avaliar a qualidade do ensino que está sendo desenvolvido em sala de aula e para tomada de decisão da gestão para melhoria do processo. O resultado pode ser avaliado pela direção da escola, visando um melhor desenvolvimento das atividades que são realizadas com as crianças da educação infantil.

Podemos levar em consideração o sucesso que foi sua aplicação, pois o modelo proposto obteve seu êxito que foi a utilização pelas crianças que participaram do estudo, devemos levar em consideração que as crianças atuais possuem mais afinidade com aparelhos digitais que seus pais quando eram crianças.

A tecnologia desperta um grande interesse nas crianças atuais, não temos como deixa-las fora do mundo virtual, pois o uso de aparelhos tecnológicos desperta na criança a curiosidade, o desejo de adquirir conhecimento, pode melhora a atenção e concentração. Mas, como pais e educadores devemos sempre monitorar o uso de novas tecnologias pelas nossas crianças, pois todo e qualquer instrumento tem seu lado bom e ruim, cabendo a nós checar sua utilização.

Em síntese o estudo buscou fazer uma análise do processo de desenvolvimento do aprendizado da matemática na unidade de educação, através de um software referente ao conhecimento dos numerais, como também o grau de conhecimento da matemática pela criança e como o educador está realizando o desenvolvimento do aprendizado em sala de aula.O presente estudo possibilitou a aplicação de um modelo que pode ser utilizando pela unidade para avaliar o aprendizado da criança da educação infantil.

Os dados ajudará o gestor da escola na tomada de decisão para a melhoria contínua do processo de ensino e desenvolvimento do aprendizado da educação infantil, pois a junção das ferramentas da qualidade com o ciclo PDCA, só surtirá efeito quando existe o desejo de todos pela melhoria contínua. O modelo de software que foi desenvolvimento para as crianças de idade entre 04 e 05 anos e o processo de validação do software não 
se exaurem, todavia, tendo em vista que o estudo foi realizado em um contexto específico, sugerem-se novas pesquisas:

$>$ Fazer um estudo semelhante em outra escola: para avaliar o conhecimento de outras crianças da mesma idade e permitiria avaliar também a aplicabilidade do software;

> Realizar um estudo do software desenvolvido, buscando melhorias como: criação de uma nova versão para o sistema que poderá ser utilizado em telefones celulares e que tenha áudio para se buscar maior interatividade com a criança.

Para academia foi relevante esse estudo, por em prática uma ferramenta que irá auxiliar no processo de aprendizagem das crianças que estão nos anos inicias da educação infantil, considerando que através da ferramenta será possível medir como está sendo assimilado o conteúdo que está sendo ministrado pelo educador em sala de aula e auxiliar a gestão na tomada de decisão para a melhoria do processo de ensino da educação infantil. Enfim, o estudo não só beneficiará a escola na qual foi objeto de estudo, mas a academia e a sociedade, pois permitirá a realização de novos estudos visando publicações e criação de patente que visam à melhoria do ensino para as crianças dos anos inicias da educaçãoinfantil e para a Engenharia de Produção, enquanto ciência que estuda as organizações pode dar uma grande contribuição para aprimoramento dos serviços direcionados a educação.

\section{Referências}

[1] Zeithaml, Valarie A.; Biltner, Mary Jo. Marketing de Serviços: a empresa com foco no cliente. 2.ed. Porto Alegre: Bookman, 2003.

[2] Cobra, Marcos; Rangel, Alexandre. Serviços ao cliente: uma estratégia competitiva. 2ed. São Paulo: Marcos Cobra, 1993.

[3] Albrecht, K., \& Bradford, L. J. (1992). Serviços com qualidade: a vantagem competitiva. In Serviços com qualidade: a vantagem competitiva. Makron

[4] Nunes, M. F. R., Corsino, P., \& Didonet, V. (2011). Educação infantil no Brasil.

[5] Fenep - Federação Nacional das Escolas Particulares 2012. Disponível em: http://www.fenep.org.br/wpcontent/uploads/2012/09/Pesquisa-Ibope.pdf. Acesso em 13 de set 2016.

[6] Kappel, M. D. B., Carvalho, M. C., \& Kramer, S. Perfil das crianças de 0 a 6 anos que frequentam creches, pré-escolas e escolas: uma análise dos resultados da Pesquisa sobre Padrões de Vida/IBGE. Revista Brasileira de Educação, 2000.

[7] Kohli, N., Sullivan, A. L., Sadeh, S., \&Zopluoglu, C. Longitudinal mathematics development of students with learning disabilities and students without disabilities: A comparison of linear, quadratic, and piecewise linear mixed effects models. Journa

[8] Soto-CalvoGinsburg, H. P., Lee, J. S., \& Boyd, J. S. Mathematics Education for Young Children: What It Is and How to Promote It. Social Policy Report.Society for Research in Child Development, 22(1), 2008.

[9] Antunes, C. Educação infantil: prioridade imprescindível. São Paulo: Vozes, 2006.

[10] Hooper, S., \&Rieber, L. P. (1995). Teaching with technology. Teaching: Theory into practice, 2013, pp.154-170.

[11] Jung, C. F. (2010). Elaboração de projetos de pesquisa aplicados a engenharia de produção. Taquara: FACCAT.

[12] Barros, Barros, A. J. D. S. \& Lehfeld, N. A. D. S. (2007). Fundamentos de metodologia científica. São Paulo.

[13] Günther, H. Pesquisa qualitativa versus pesquisa quantitativa: esta é a questão. Psicologia: teoria e pesquisa, 22(2), 2006, 201210 .

[14] Moresi, E. (2003). Metodologia da pesquisa. UniversidadeCatólica de Brasília.

[15] Gil, Antonio Carlos. Como elaborar projetos de pesquisa. 4. ed. São Paulo: Atlas, 2002.

[16] Levine, D. M., Berenson, M. L., \& Stephan, D. (2005). Estatística: teoria e aplicações-usando Microsoft Excel português. Ltc.

[17] Cassol, A. P., Raszl, S. M., Silveira, I. H., Siemeintcoski, M. E., Arruda, S. R., \& da Silva, S. B. (2012). Gestão da qualidade na educação. Revista E-Tech: Tecnologias para Competitividade Industrial-ISSN-1983-1838, 15-33.

[18] Xavier, AC da R. Uma agenda para a melhoria da gestão da qualidade na educação brasileira. Brasília: IPEA, n. 4795, 1995.

[19] UNICEF. The Convention on the Rights of the Child, 1989. Disponível em: <http://www.unicef.org.uk/Documents/Publicationpdfs/UNCRC_PRESS2009 10web .pdf>. Acesso em: 02 nov. 2015.

[20] Longo, R. M. J. (2009). Gestão da qualidade: evolução histórica, conceitos básicos e aplicação da educação. 1996. Acesso em, 19.

[21] Veiga, I. P. (2003). Inovações e projeto político-pedagógico: uma relação regulatória ou emancipatória. UNICAMP, Caderno CEDES, Campinas, 23(61), 267-281.

[22] Ifrah, Georges. Os números. Globo Livros, 2005

[23] Boyer, C.B. 1999. História da matemática. São Paulo, Edgard Blücher Ltda, 488 p.

[24] Lopes, F. R. F. (2016). Software educativo, lúdico e interativo, como recurso didático em apoio à construção do conceito de número por crianças em processo de alfabetização matemática.

[25] Ramani, G. B., Zippert, E., Schweitzer, S., \& Pan, S. Preschool children's joint block building during a guided play activity. Journal of Applied Developmental Psychology, 35(4), 2014, 326-336

[26] Kishimoto, T. M. (2010). Alfabetização e letramento/literacia no contexto da educação infantil: desafios para o ensino, para a pesquisa e para a formação. Múltiplas Leituras, 3(1-2), pp.18-36. Recuperado em 18, abril, 2015, de http://dx.doi. org/10.15603/1982-8993/ml.v3n1-2p18-36 
[27] Fidalgo-Neto, A., Tornaghi, A. J. C., Meirelles, R. M. S., Berçot, F. F, Xavier, L. L., Castro, M. F. A. \& Alves, L. A. (2009). The use of computers in Brazilian primary and secondary schools. Computers \& Education, 53(3), 677-685.

[28] Roschelle, J. M., Pea, R. D., Hoadley, C. M., Gordin, D. N., \& Means, B. M. (2000). Changing how and what children learn in school with computer-based technologies. The future of children, 76-101.

[29] Avalos, B. \&Assael, J. (2006). Moving from resistance to agreement: The case of the Chilean teacher performance evaluation. International Journal of Educational Research, 45(4), 2006, 254-266.

[30] Papert, S. (1980). Mindstorms: Children, computers, and powerful ideas. Basic Books, Inc.

[31] Arenson, R. L. (1986). Teaching with computers. Radiologic Clinics of North America, 24(1), 97-103.

[32] Aragão, D. S.\& Enez, E. (2010). Jogos educativos com o uso do computador na educação infantil. Recuperado em 15, outubro, 2015, de<http://docplayer.com.br/9168572-Jogos-educativos-com-o-uso-do-computador-na-educacao-infantil-1.html.

[33] Sarama, J., \& Clements, D. H. (2004). Building blocks for early childhood mathematics. Early Childhood Research Quarterly, 19(1), 181-189.

[34] Almeida, M. D. \& VALENTE, J. A. (2011). Tecnologias e currículo: trajetórias convergentes ou divergentes. São Paulo: Paulus.

[35] Tomi, A. B., \&Rambli, D. R. A. An interactive mobile augmented reality magical playbook: learning number with the thirsty crow. Procedia Computer Science, 25, 2013, 123-130.

[36] Social, F. P. E. Referencial Curricular Nacional para a Educação Infantil.

[37] Felicia, P. (2009). Digital games in schools: Handbook for teachers. Acesso em Agosto de 2016.

[38] Brom, C., Preuss, M., \&Klement, D. (2011). Are educational computer micro-games engaging and effective for knowledge acquisition at high-schools? A quasi-experimental study. Computers \& Education, 57(3), 1971-1988.

[39] Fonseca, L. M. M., Góes, F. D. S. N. D., Ferecini, G. M., Leite, A. M., Mello, D. F. D., \& Scochi, C. G. S. (2009). Inovação tecnológica no ensino da semiotécnica e semiologia em enfermagem neonatal: do desenvolvimento à utilização de um software educacional. Texto \& Contexto-Enfermagem, 18(3), 542-548.

[40] Alavarce, D. C., \& Pierin, A. M. G. (2011). Development of educational hypermedia to teach an arterial blood pressure measurement procedure. Revista da Escola de Enfermagem da USP, 45(4), 939-944.

[41] Lopes, A. C. C., de Andrade Ferreira, A., Fernandes, J. A. L., da Silva Morita, A. B. P., de Brito Poveda, V., \& de Souza, A. J. S (2011). Construção e avaliação de software educacional sobre cateterismo urinário de demora. Revista da Escola de Enfermagem da USP, 45(1), 215-222.

[42] Botti, N. C. L., Mesquita, I. R., Pereira, C. C. M., \& Araújo, F. A. (2014). Desenvolvimento e validação de software educativo de saúde mental. Revista Mineira de Enfermagem, 18(1), 218-223.

[43] Iwata, B. F., \& Araújo, M. C. S. (2016). Ferramenta Educativa como Instrumento de Conscientização sobre a Política Nacional de Resíduos Sólidos. Anais dos Simpósios de Informática do IFNMG-Campus Januária, (2).

[44] Carpinetti, L. C. R. (2010). Gestão da qualidade: conceitos e técnicas. Atlas.

[45] Batalha, M. O. (2008). Organizador. Introdução à Engenharia de Produção: Elsevier.

[46] Corrêa, H. L., \& Corrêa, C. A. (2000). Administração de Produção E Operações: Manufatura e Serviços: Uma Abordagem Estratégica . Editora Atlas SA.

[47] Peinado, J., \& Graeml, A. R. (2007). Administração da produção. Operações industriais e de serviços. Unicenp.

[48] Werkema, M. C. C., \& Aguiar, S. (1996). Planejamento e análise de experimentos: como identificar e avaliar as principais variáveis influentes em um processo. Belo Horizonte: Fundação Christiano Ottoni, Escola de Engenharia da UFMG

[49] Montgomery, D. C. (2009). Introdução ao controle estatístico da qualidade. Introdução ao controle estatístico da qualidade. Tradução Ana Maria Lima de Farias, Vera Regina Lima de Farias e Flores; Revisão técnica Luiz da Costa Laurencel. Rio de Janeiro: LTC, 4.

[50] Brito, G. D. S., \& Da Purificação, I. V. O. N. E. L. I. A. (2008). Educação e novas tecnologias. Editora Ibpex.

[51] Behr, A., Moro, E. L., \& Estabel, L. B. (2008). Gestão da biblioteca escolar: metodologias, enfoques e aplicação de ferramentas de gestão e serviços de biblioteca. Ciência da Informação, Brasília, 37(2), 32-42. 